\title{
Influence of industrial design on competitiveness of enterprise product
}

\author{
Yiding $\mathrm{Bu}^{1}$, Jiajun Li \\ ${ }^{1}$ School of Art and Design, Liaoning Shihua University, Fushun, Liaoning, 113001, China
}

\begin{abstract}
With the continuous improvement of industrial technology in the world and the intense competition in the marketing of globalization, the demand for diversified and complex products from enterprises provides an opportunity for research and development of industrial design. By tapping its trends and development prospects from a variety of angles, it recognized the significance of industrial design to the competitiveness of enterprise product more in-depth. This article puts forward to the necessity and importance of industrial design for the competitiveness of the enterprise products, in order to provide the theory basis for enterprise products about how to combine industrial design to improve competitiveness.
\end{abstract}

\section{Introduction}

Industrial design is centred on product design innovation, revolving around product appearance and modeling, aiming at establishing value of product brand, increasing product added value, and enhancing product competitiveness, which is a medium constructing communication between products and consumers[1]. Excellent industrial design can promote product sales, widen the difference with similar products and competitors, and remain invincible position in the competitive market competition.

\section{Industrial design can enhance brand value and establish brand image}

\subsection{Meeting market demand}

The factor for market demand is one of the main reasons for the development of product form, which is mainly reflected by the improvement of people's living standards and material needs, and the customers' ability to understand and identify has also been significantly improved. In the current consumer market, the perceptual functions of products have became an important factor affecting consumer consumption[2]. The development and transformation of product forms have also been stimulated to a certain extent. Product form is the most direct way of embodying perceptual factors. Product image design has become an important source of competitiveness for many companies. Under the influence of this external environment, the reality of survival of the fittest is also placed in front of various enterprises. Only by bringing the product form closer to market demand can it survive. Industrial design is the integration and innovation of the appearance, function, structure, packaging and branding of industrial products. It is the combination of technological knowledge, artistic knowledge and economic knowledge. With the development of high technology, product quality is no longer the main contradiction, many mainstream brands actively promote industrial design innovation, to guide the development trend of industrial design, seizing the market.

From a consumer's perspective, building a good image is particularly important for companies. Product modeling is the language expressing product design ideas and medium implementing product features. Through modeling design, the product can convey the meaning and symbolism of spirit, culture and other levels. Under the condition that the product forms and functions are basically similar, companies with good image can be accepted and recognized by the market faster, consumers are more inclined to products with good brand and reputation, which can greatly improve the competitiveness of the company and consolidate market position in the fierce market competition[3]. In particular, with the continuous improvement of people's living standards and the increasingly diversified and personalized of consumer needs, product brands and corporate image will have an important impact on consumer purchases. In a material-rich society, people rarely pay much attention to product prices, and the differences between products are less than the similarities. Therefore, brand and corporate image become more important than price and product. From the perspective of the enterprise, to establish a good image becomes more and more important.

\footnotetext{
* Corresponding author: 17053530@qq.com
} 


\subsection{Helping brand to increase product sales}

Modern industrial design is an important tool for dissemination of economic information and a form of corporate publicity. The purpose of industrial design is to promote the brand. The measure planning promotion of products for increasing brand awareness, has become a major strategy by major companies[4]. The target market varies according to continuous promotion of products. At the beginning of marketing the product, promotions give priority to brand for being recognized quickly and increasing the brand awareness[5]. The core competence of an enterprise is the commercialization of brand competitiveness in the market. Brand is a sign of products and services. Enterprises must not only design beautiful and practical potential products, but also utilize good design to promote the upgrading of brand competitiveness. Therefore, brand is the most effective way to test the core competence of an enterprise.

The task of industrial design is to make full use of all kinds of materials, technical conditions and scientific and technological achievements according to the needs of society, pay attention to the relationship between products and people, and work closely with engineers and technicians in the process of determining the quality of appearance, so that the material and spiritual functions of products constantly bring greater use value and economic benefits for consumers. Good products will be quickly accepted by the market and consumers, leaving a good impression in the minds of consumers, while creating huge economic and social benefits. The determinants of the brand's core competitiveness are the main criteria for measuring the brand's core competitiveness, the ability to meet customer needs and maintain customer relationships. With customer satisfaction, enterprise sales and profits can increase, brand competitiveness and popularity can be improved; otherwise, everything is empty, the core competitiveness of the brand to customer satisfaction as the destination.

\subsection{Building brand image}

Branding begins with a clear indication to the audience of the company's name, culture, brand image, and brand strengths, which are primarily conveyed through the product, as well as the corporate image. Brand competitiveness is the combined materialization and commodification of a company's core competencies in the market, and industrial design is the bridge between the company and the consumer. The purpose of industrial design is to uncover consumers' feelings and needs for a product and, accordingly, to create a new product development system driven by consumers. Consumers receive information about many products every moment, so their perception of the product image is always changing. Consumers are no longer satisfied with just the basic functionality of the product. To design a product with a distinctive and unique image, not only does it have to constantly draw the attention of consumers to the image of the product, but it also has to make consumers benefit from the purchase of some additional services added after use, so that consumers get some benefit from the use and mental satisfaction, it will form a distinctive inner impression in their mind. The more distinctive the product's brand features, the more obvious the consumer's awareness will be. True efficiency, wholeness and durability are the important rewards that product brand image brings in the market economy competition. Product brand has the role of enhancing the value, become the driving force for the development and growth of enterprises.

\section{Industrial design can impact innovative of enterprise products, enhance the competitiveness of enterprise products}

\subsection{Bringing Product innovation}

Industrial design is the soul of an enterprise[6]. Industrial design is the link between high technology and daily life, the bridge between enterprises and consumers, and the medium for creating good products. Good products can effectively open up the difference among products and create high added value. The purpose of industrial design is to innovate products to meet market demand. The essence of design is innovation. In the increasingly fierce competition in the globalized economy, the demand for innovation in industrial design is the most active and numerous[7]. Innovative design is becoming an important resource for business operations. Table 1 shows the market scale of industry design in China, which demonstrates the function industry design brings.

Table 1. Market scale of industrial design in China ${ }^{\mathrm{a}}$.

\begin{tabular}{cc}
\hline Year & Hundred Million(RMB) \\
\hline 2019 & 1989 \\
2020 & 2590 \\
2021 & 3330 \\
2022 & 4174 \\
2023 & 5083 \\
\hline
\end{tabular}

${ }^{a}$ Data source: OCN Industry Research Center

With the intensifying competitive environment and the development of globalization, under the continuous flow of new products, more and more companies have made this process main strategy to improve product development and innovation, shorten the design cycle, reduce the design cost, quickly launch new products and quickly capture the market. The continuous development of society and the ever-changing science and technology are promoting the development and change of design. Design is the medium that transforms scientific and technological achievements into actual productivity. The core of design is innovation, and the ultimate goal is to realize value[8]. The practice of development in developed countries shows that industrial design has become one of core driving forces for enterprise competition to maximum economic benefits. Especially in the case of deepening economic globalization and fierce competition in the international market, the 
capability in product design and development is the vital factor for the international competitiveness of products. Innovation is the driving force behind the progress and development of human society, which is attracting more attention nowadays[9]. The function and mission of industrial design is to discover the market demand, to strive to meet the market demand from the existing material and technical conditions, and to create the market demand, It is the progress combining the material and mental functions to adapt to the market demand and strive to satisfy both consumers and manufacturers. It is one of the key aspects of enhancing the market competitiveness of enterprises and is an important aspect of enriching the material and cultural life of society.

\subsection{Giving products higher added value}

Good design can improve product quality and enhance the competitiveness of the enterprise. Industrial design can maximize the value of the product under the premise of obtaining normal profits for the company, thereby greatly improving the economic efficiency of the enterprise. Constantly updating the technology and excellent avant-garde design are both ways for the product to create added value. The product with advanced technology can quickly surpass similar products to achieve a leading position in similar products under the premise of certain material functions. Focusing on the styling of industrial products can increase the added value of the product.

Creating added value through technology is not to say that it works on all products, but industrial design is different and can involve both extremely simple products and large, high-end products. Industrial design not only makes the products more excellent, but also makes the products have richer and deeper cultural connotations, like simple and comfortable operation mode, scientific and reasonable human-machine relationship, attractive aesthetic form, personalized design style, accurate symbolic meaning and ecological product creativity. The good design endows the product with features of subjectivity, individualization, emotion and ecology, which are recognized by customers, creating a considerable value-added product. therefore, the added value that industrial design can create is beyond the reach of any product component.

\section{Industrial design can effectively meet the aesthetic needs of consumers and increase product sales}

Nowadays, with the continuous advancement of the society and technology, enterprises must not only design beautiful and practical best-selling products, but also use good design to promote the upgrading of brand competitiveness [10]. As people's living standards continue to improve, materials are becoming more abundant, the quality of life is advancing by leaps and bounds, and lifestyles are certain to be the direction in the developing of beauty and comfort. The process of people pursuing a colourful life through industrial product design is a realization and reflection of nature and self-worth. Table 2 shows how the design influences customers' perception of brand before price level. In the increasingly rich environment of today's commodity economy, with the purpose of multi-functional and multilevel needs, the consumption structure based on aesthetic viewpoint of harmony between industrial design and social is quietly pushing the entire economy forward[11].

Table 2. Vacuum cleaner Share of Sale in China in March $2020^{\mathrm{a}}$.

\begin{tabular}{ccc}
\hline Brand & Share of Sale & Average Price (RMB) \\
\hline Dyson & $46.17 \%$ & 3413 \\
ECOVACS & $13.79 \%$ & 1846 \\
Supor & $8.7 \%$ & 1277 \\
\hline${ }^{a}$ Data source: AVC-bigdata &
\end{tabular}

The spread of the Internet and technological advances has led to the release of consumer demand for new products. The demand for products has become diversified and individualized, mass-produced products are fewer and fewer, and the mass production of single product categories is gradually moving away. A single functional design form can no longer meet the everchanging market demand, and it is imperative to adapt to change. Product form innovation is the most direct embodiment of product innovation[12]. A good product can use its extraordinary aesthetic power to enhance the appeal to immerse consumers in the joy of product image and functions, led customers to accept the guidance of the product consciously, thereby increasing product sales. Therefore, industrial design is the aesthetic re-creation of material culture and lifestyle. Industrial design can beautify the product to make it conform to people's aesthetic taste, and effectively guide its consumption concept in material culture and lifestyle. The concept of industrial design and evaluation criteria need to focus on the real sense of product innovation, to meet people's physical and psychological needs, while creating a harmonious human way of life. Industrial design is about creating a better world by responding to social, economic, environmental and ethical aspects.

\section{Conclusion}

Industrial design reflects the needs of the industrial industry and society at specific period, which put forward higher requirements and expectations for industrial design, and promote the development of design, pushing industrial design in the direction of diversification, optimization and systematization. Industrial design occupies an increasingly important position in the enterprise, it is the source of the core competitiveness of products. It provides a concrete and operable basis for the realization of the company's overall image goal, so that the company can demonstrate its personality and strengthen its overall quality in many aspects such as business reputation, brand awareness, business strategy, sales service, employee quality, and corporate culture. Industrial design also enhances the competitiveness of the enterprise's economic innovation 
and development, and promote the development of highquality, high-quality, and high-value-added in the manufacturing of enterprise products.

\section{References}

1. Li, J. (2014) Interpretation of packaging design thinking in brand redesign. packaging engineering, 35: 9-12.

2. Su, J.N., Wang P., Zhang S.T., Zhao X.S., Zhou A.M. (2013) Research progress on key technologies of product image modeling design. Mechanical Design, 30: 97-100.

3. Liang L.L. (2009) Product conceptual design. Higher Education Press, Beijing.

4. Hao Z., Zhang W. (2011) Talking about detail design and brand building in industrial design. Art Education, 12: 142-143.

5. Liu X. (2011) Good Design, Good CommoditiesEvaluation of Industrial Design. China Building Industry Press, Beijing.

6. Li L., Xu Z.R., Zhao L. (2008) Research on the classification of complex product design methods. Mechanical Design, 25: 1-32.

7. Jiang H.B. (2012) The internal mechanism of industrial design innovation. Decoration, 4: 27-30.

8. Zhang R. (2010) On Industrial Design and Creative Industry. Dongyue Tribune, 31: 85-88.

9. Jiang W. (2010) A summary of product innovation design theory and methods. Packaging Engineering, 31: $130-134$

10. Ma Z.Z. (2013) Enterprise product competitiveness and effective design management. Market Weekly (Theoretical Research), 10: 14-15.

11. Yuan T. (2011) Industrial product modeling design. Peking University Press, Beijing.

12. Pan P., Yang S.X. (2012) Research status and trends of product form innovation design and its evaluation system. Mechanical Design, 29: 1-5. 